03.4

\title{
Особенности динамики струйного потока, генерируемого при поверхностном кипении жидкости на лазерном нагревателе
}

\author{
(C) А.В. Кулик ${ }^{1,2}$, С.Н. Мокрин ${ }^{1,2}$, А.М. Краевский ${ }^{2}$, С.С. Минаев ${ }^{1}$, М.А. Гузев ${ }^{1}$, В.М. Чудновский ${ }^{1}$ \\ ${ }^{1}$ Институт прикладной математики ДВО РАН, Владивосток, Россия \\ 2 Дальневосточный федеральный университет, Владивосток, Россия \\ E-mail: Kulik_av@dvfu.ru
}

Поступило в Редакцию 6 июля 2021 г.

В окончательной редакции 1 октября 2021 г.

Принято к публикации 1 октября 2021 г.

\begin{abstract}
Экспериментально обнаружено, что нагретые затопленные струи, возникающие при пузырьковом лазероиндуцированном кипении воды на поверхности торца оптоволокна, погруженного в жидкость, с увеличением мощности лазерного излучения (теплового потока) экспоненциально уменьшают свою скорость. Этот результат получен в замкнутой кювете круглой формы, в которой разогретые струи, сталкиваясь со стенками, обтекают границы кюветы, передавая ей свое тепло. Полученный результат важно учитывать при проведении лазероиндуцированной прецизионной очистки поверхностей в замкнутых объемах, разработке медицинских технологий лазерного хирургического лечения патологически измененных сосудов, кист и в других приложениях.
\end{abstract}

Ключевые слова: лазерное излучение, затопленная струя, кипение, пузырьки, полость, теплоперенос.

DOI: 10.21883/PJTF.2022.02.51944.18949

Тепловые эффекты, вызванные лазерным излучением, доставляемым по оптоволокну, привлекают большое внимание в связи с широчайшим использованием оптоволоконной техники в технических приложениях и, особенно, в медицине. В связи с этим большой интерес представляет лазерный нагрев жидкостей вблизи кончика оптоволокна, погруженного в жидкость. На выходе из волокна при его диаметре по кварцу 100-600 $\mu$ m даже при низких значениях мощности лазерного излучения на торце оптоволокна можно сформировать гигантский тепловой поток, исчисляемый десятками $\mathrm{MW} / \mathrm{m}^{2}$. В таком случае жидкость быстро нагреется до температуры насыщения и вскипит. В практических приложениях наибольший интерес представляет вода. Если торец оптоволокна покрыть тонким слоем вещества, поглощающего излучение (чернение торца), то нагрев этого слоя приведет к поверхностному кипению воды, не зависящему от длины волны падающего излучения. Если подобрать длину волны лазерного излучения, которое эффективно поглощается в воде, то без чернения в окрестности кончика оптоволокна можно инициировать объемное вскипание.

Если кипение локализовано вблизи торца лазерного оптоволокна, а остальная окружающая жидкость будет холодной, то пар в нарастающих вблизи торца пузырьках в какой-то момент начнет конденсироваться быстрее, чем генерироваться. В этот момент рост пузырьков прекращается, и они начинают схлопываться. Такое кипение называют кипением, недогретым до температуры насыщения [1]. В отличие от развитого кипения кипение с недогревом сопровождается не только ростом парогазовых пузырьков, но и их схлопыванием, что мо- жет приводить к генерации затопленных кумулятивных струй разогретой жидкости, направленных от поверхности нагревателя в объем жидкости [2].

Затопленные струи возникают при схлопывании пузырьков несферической формы либо в случае потери сферичности в процессе коллапса [2-6]. Для таких пузырьков столкновение радиальных потоков жидкости, движущейся за стенками пузырька, приводит к конверсии радиального движения в аксиальные затопленные струи [2-6]. Эти струи получили широкое применение в технических приложениях и, особенно, в медицине [7-12]. Ввиду большой практической значимости исследования свойств разогретых затопленных струй, возникающих при кипении жидкости, являются актуальными.

В настоящей работе использовался полупроводниковый лазер с длиной волны излучения $0.97 \mu \mathrm{m}$. Излучение проводилось по кварц-кварц-полимерному волокну диаметром $600 \mu \mathrm{m}$. Проксимальный конец оптоволокна (световода) соединяли с источником лазерного излучения, работающего в непрерывном режиме. Эксперименты проводились при мощностях лазерного излучения $7,5,3,1.5,1,0.5 \mathrm{~W}$. Поскольку для длины волны лазерного излучения $0.97 \mu \mathrm{m}$ поглощение в воде является очень слабым (показатель поглощения $0.47 \mathrm{~cm}^{-1}$ [13]), торец оптоволокна предварительно покрывался слоем поглощающего излучение вещества - оксида двухвалентного железа $(\mathrm{FeO})$. В отличие от слоя аморфного углерода [14] покрытие из оксида железа продемонстрировало высокую стойкость к ударным нагрузкам, возникающим в процессе формирования кумулятивной струи. 

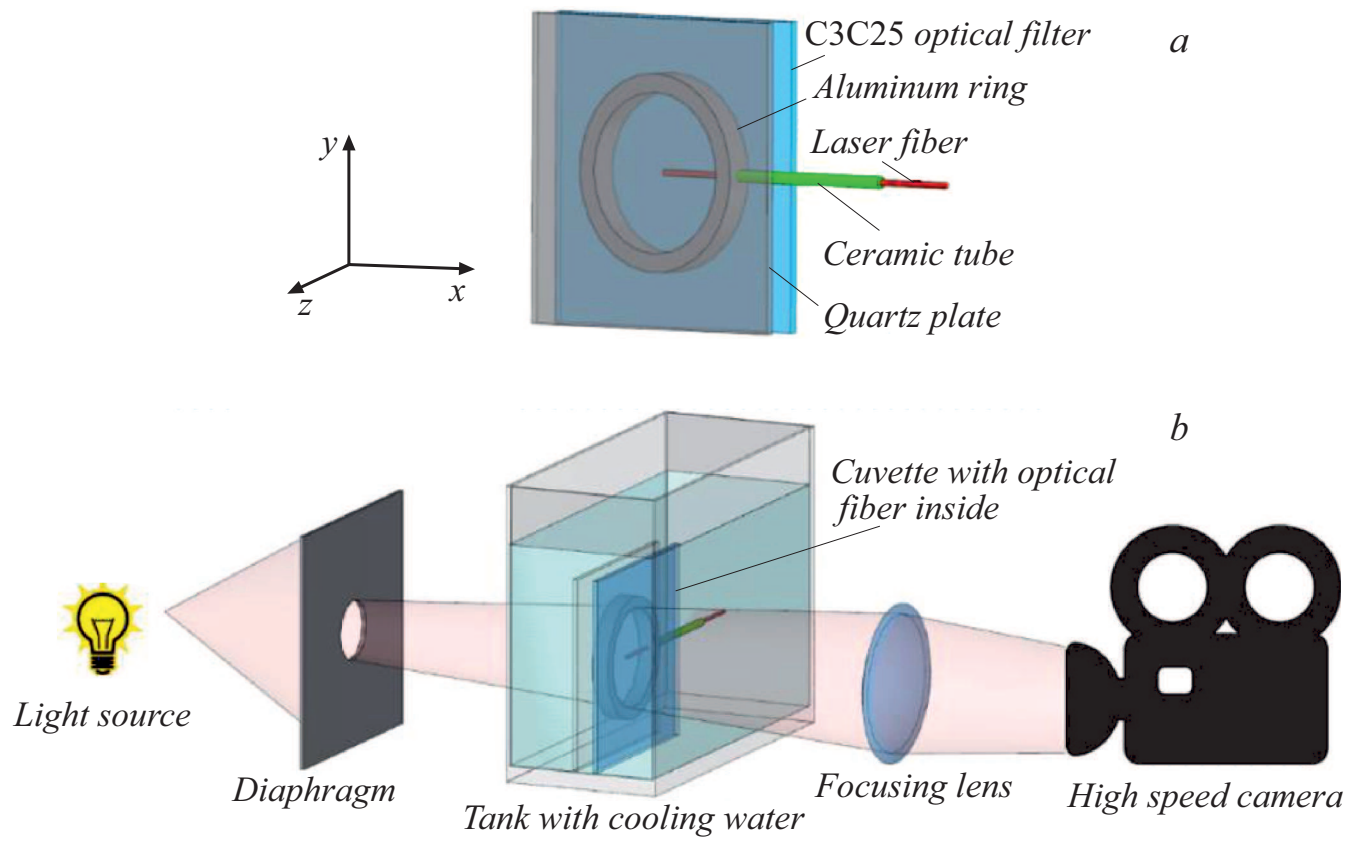

Pис. 1. Схема экспериментальной установки.

Исследование проводилось в цилиндрической кювете объемом $2.3 \mathrm{~cm}^{3}$ (рис. $1, a$ ). Внутренний объем кюветы был образован с помощью алюминиевого кольца высотой $4.4 \mathrm{~mm}$, внутренний диаметр которого равен $26 \mathrm{~mm}$, а внешний $-32 \mathrm{~mm}$. К одному из оснований цилиндра была приклеена кварцевая пластина толщиной $1.3 \mathrm{~mm}$, к другому - светофильтр С3С25 с полосой пропускания $280-900 \mathrm{~nm}$, что позволило отсечь излучение, испускаемое лазером во время видеосъемки. В алюминиевом кольце сбоку было проделано сквозное отверстие для установки тонкой керамической трубки, через которую в кювету вводили оптоволокно. Оптоволокно устанавливалось горизонтально в центре рабочей кюветы, наполненной бидистиллированной водой при температуре $293 \mathrm{~K}$, на расстоянии $13 \mathrm{~mm}$ от торца оптоволокна до стенки кюветы. С целью охлаждения рабочая кювета помещалась в прозрачную емкость с водой размером $100 \times 100 \times 50 \mathrm{~mm}$. Видеосъемка проводилась с использованием скоростной видеокамеры Photron Fastcam SA-Z со скоростью $1000 \mathrm{fps}$ при разрешении $1024 \times 1024$ пикселя. Для подсветки использовался лазерный диод с длиной волны излучения $650 \mathrm{~nm}$, световой поток от которого направлялся на матрицу камеры через диафрагму. Рабочая кювета была установлена в охлаждающем бассейне между лазерным диодом и камерой таким образом, чтобы стенка кюветы, выполненная из светофильтра, была обращена в сторону камеры. Изображения теневой картины проецировали непосредственно на матрицу видеокамеры с помощью линзы. Схема экспериментальной установки представлена на рис. $1, b$.
В экспериментах измерялось время, за которое в зависимости от мощности лазерного излучения фронт струи, движущейся от торца оптоволокна, достигал стенки кюветы, проходя расстояние $13 \mathrm{~mm}$. Разделив это расстояние на полученное время, находим среднюю скорость, с которой тепло, содержащееся в струе, достигает стенки кюветы. Этот параметр представляет основной интерес в лазерных технологиях интерстициального лечения истинных кист.

На рис. 2 в верхнем ряду показаны затопленные струйные потоки разогретой жидкости, полученные в результате недогретого кипения на торце оптоволокна при различных мощностях лазерного излучения. Затопленные струи направлены от торца к боковой стенке кюветы, где они сталкиваются со стенками кюветы и растекаются вдоль ее поверхности. При нагреве жидкости меняется ее плотность, что хорошо определяется на изображении, полученном „на просвет“ в виде затемненных участков на фоне недогретой жидкости. В нижнем ряду на рис. 2 изображено распространение нагретой струи жидкости в различные моменты времени при мощности лазерного излучения, равной $3 \mathrm{~W}$.

Картина кипения с образованием струйных потоков существенно зависит от мощности лазерного излучения. Эта зависимость отображена на рис. 3. На этом рисунке приведены осредненные значения скорости распространения нагретой струи и указаны доверительные интервалы. Здесь показано, как меняется скорость, с которой передний фронт струи достигает боковой стенки кюветы, в зависимости от мощности лазерного излучения. Из рис. 3 следует, что существует порог мощности, разграничивающий область свободной конвекции и об- 

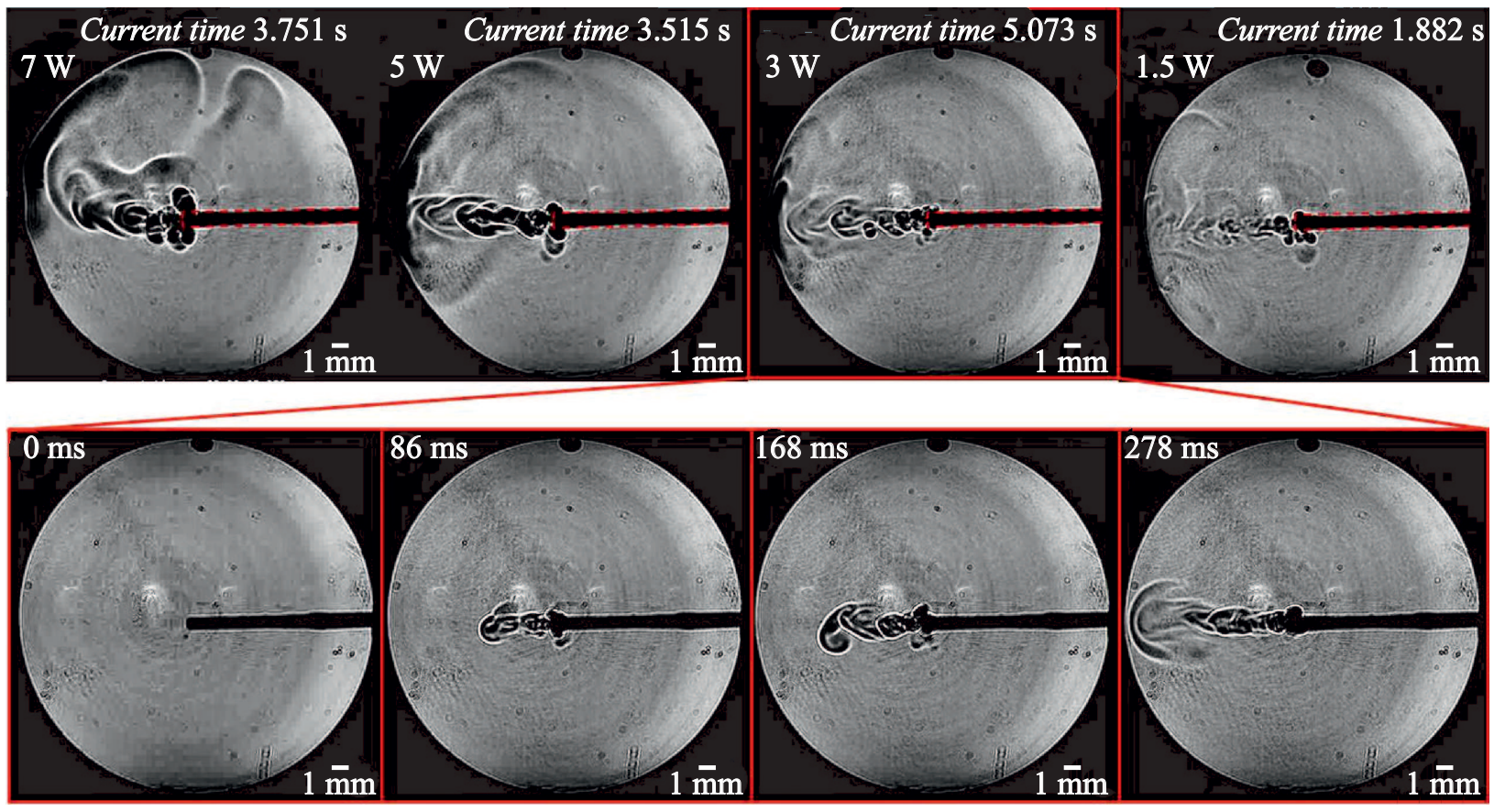

Рис. 2. Фотоизображение затопленных струй горячей жидкости внутри кюветы при разных значениях мощности лазерного излучения спустя различное время после начала эксперимента: через $3.751 \mathrm{~s}$ для $7 \mathrm{~W}, 3.515 \mathrm{~s}$ для $5 \mathrm{~W}, 5.073 \mathrm{~s}$ для $3 \mathrm{~W}$ и $1.882 \mathrm{~s}$ для $1.5 \mathrm{~W}$ (верхний ряд). Нижний ряд - распространение нагретой струи для различных моментов времени при мощности лазера $3 \mathrm{~W}$. Штриховой линией обозначен контур оптоволокна. Скорость съемки $1000 \mathrm{fps}$.

ласть кипения воды (вертикальная штриховая линия), а скорость, с которой передний фронт струи достигает боковой стенки кюветы, экспоненциально уменьшается при увеличении мощности излучения.

В области свободной конвекции, когда мощность излучения равна $0.5 \mathrm{~W}$ (ниже порога кипения), скорость, с которой нагретая жидкость достигает стенки кюветы, является наименьшей из всех $(\sim 0.4 \mathrm{~cm} / \mathrm{s})$. При увеличении мощности излучения до $0.9 \mathrm{~W}$ и более свободная конвекция переходит в режим недогретого поверхностного (пузырькового) кипения с образованием струйных потоков разогретой жидкости. В этом случае скорость, с которой разогретая жидкость достигает стенки кюветы, резко увеличивается. Однако по мере увеличения мощности лазерного излучения эта скорость начинает экспоненциально уменьшаться. Кривая зависимости падения средней скорости струи от мощности лазерного излучения экстраполируется экспоненциальной зависимостью вида

$$
V=21.5 \exp (-0.454 W)
$$

При дальнейшем увеличении мощности лазерного излучения кипение станет пленочным. Пленочное кипение возникает, когда паровой пузырек полностью охватывает поверхность теплового источника (торец оптоволокна), что приводит к резкому уменьшению теплоотвода в жидкость [1]. При пленочном кипении тепло будет затрачено на нагрев торца оптоволокна, что может разогреть его до высоких температур, вплоть до температуры плавления кварца $(\sim 2000 \mathrm{~K})$.

Уменьшение скорости затопленных струй при увеличении мощности лазерного излучения (теплового потока) является неожиданным результатом, который, на наш взгляд, можно объяснить увеличением нагрева (уменьшением недогрева) окружающей торец жидкости при увеличении мощности лазерного излучения. С увеличением мощности излучения возрастает тепловой поток от торца оптоволокна в воду, что приведет к нагреву большего объема окружающей жидкости и соответственно уменьшению недогрева окружающей торец водной среды. Пузырьки, возникающие в прогретой воде, схлопываются значительно медленнее, чем в среде с большим недогревом (в более холодном окружении). Поскольку пузырьки медленнее схлопываются, скорость генерируемых струй в прогретой воде будет существенно меньшей, чем в случае более недогретой, более холодной среды $[2,6]$. При этом скорость потока, складывающегося из микроструй, также уменьшится.

Отметим, что данный результат получен при поверхностном кипении, когда вода закипает на поверхности торца оптоволокна, покрытого поглощающим излучение слоем оксида двухвалентного железа. При объемном вскипании, когда лазерное излучение эффективно поглощается водой (это излучение с длиной волны 1.94, 1.56, $1.47 \mu \mathrm{m})$, динамика струй и соответственно нагрева границ полости может быть иной. Известно, что объемное 


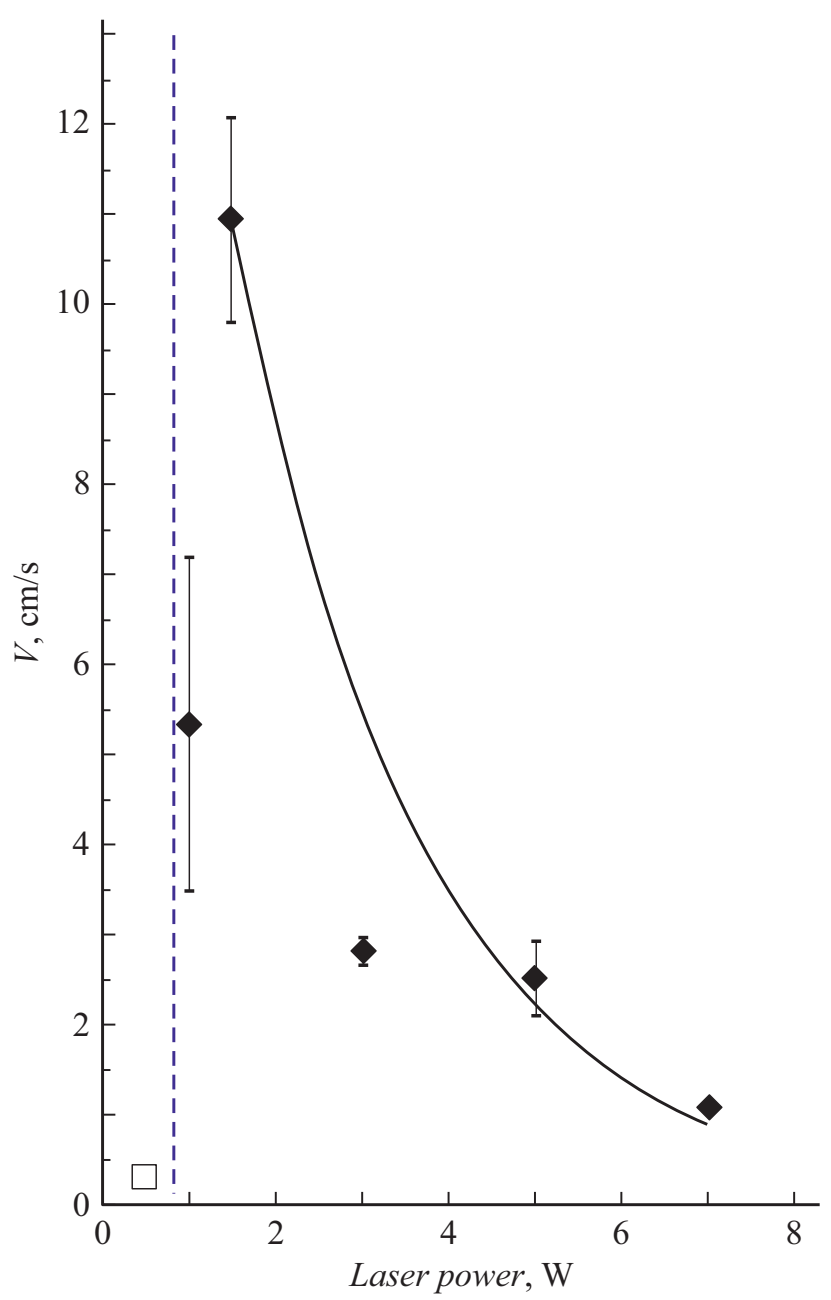

Рис. 3. Зависимость скорости, с которой струя достигает стенки кюветы, от мощности лазерного излучения. Сплошная линия - экспоненциальная аппроксимация экспериментальных данных. Штриховая линия - значение мощности лазерного излучения, при котором начинается поверхностное кипение с образованием струй.

кипение ведет к быстрому росту и коллапсу парового пузыря, что сопровождается ударными волнами (хлопками), большими скачками давления, а также приводит к быстрому повышению фоновой температуры жидкой фракции во всем ее объеме [2].

\section{Финансирование работы}

Работа выполнена при финансовой поддержке Минобрнауки РФ (грант № 075-15-2019-1878).

\section{Конфликт интересов}

Авторы заявляют, что у них нет конфликта интересов.

\section{Список литературы}

[1] С.С. Кутателадзе, Основы теории теплообмена (Атомиздат, М., 1979).

[2] V.M. Chudnovskii, A.A. Levin, V.I. Yusupov, M.A. Guzev, A.A. Chernov, Int. J. Heat Mass Transfer, 150, 119286 (2020). DOI: $10.1016 /$ j.ijheatmasstransfer.2019.119286

[3] S. Gekle, J.M. Gordillo, D. van der Meer, D. Lohse, Phys. Rev. Lett., 102 (3), 034502 (2009). DOI: 10.1103/PhysRevLett.102.034502

[4] T.T. Truscott, B.P. Epps, J. Belden, Annu. Rev. Fluid Mech., 46, 355 (2014). DOI: 10.1146/annurev-fluid-011212-140753

[5] S.W. Ohl, E. Klaseboer, B.C. Khoo, Phys. Med. Biol., 54 (20), 6313 (2009). DOI: 10.1088/0031-9155/54/20/019

[6] V.M. Chudnovskii, M.A. Guzev, V.I. Yusupov, R.V. Fursenko, J. Okajima, Int. J. Heat Mass Transfer, 173, 121250 (2021). DOI: $10.1016 /$ j.ijheatmasstransfer.2021.121250

[7] V. Robles, E. Gutierrez-Herrera, L.F. Devia-Cruz, D. Banks, S. Camacho-Lopez, G. Aguilar, Phys. Fluids., 32 (4), 042005 (2020). DOI: 10.1063/5.0007164

[8] R. Dijkink, S. Le Gac, E. Nijhuis, A. van den Berg, I. Vermes, A. Poot, C.-D. Ohl, Phys. Med. Biol., 53 (2), 375 (2008). DOI: $10.1088 / 0031-9155 / 53 / 2 / 006$

[9] S.D. George, S. Chidangil, D. Mathur, Langmuir, 35 (31), 010139 (2019). DOI: 10.1021/acs.langmuir.8b03293

[10] K.F. Chan, T.J. Pfefer, J.M.H. Teichman, A.J. Welch, J. Endourol., 15 (3), 257 (2001). DOI: $10.1089 / 089277901750161737$

[11] В.П. Минаев, Н.В. Минаев, В.И. Юсупов, А.М. Дымов, Н.И. Сорокин, В.Ю. Лекарев, А.З. Винаров, Л.М. Рапопорт, Квантовая электроника, 49 (4), 404 (2019). [V.P. Minaev, N.V. Minaev, V.I. Yusupov, A.M. Dymov, N.I. Sorokin, V.Yu. Lekarev, A.Z. Vinarov, L.M. Rapoport, Quantum Electron., 49 (4), 404 (2019). DOI: $10.1070 /$ QEL16809].

[12] Ф.В. Бункин, М.И. Трибельский, УФН, 130 (2), 193 (1980). DOI: 10.3367/UFNr.0130.198002a.0193 [F.V. Bunkin, M. Tribel'skii, Sov. Phys. Usp., 23 (2), 105 (1980). DOI: 10.1070/PU1980v023n02ABEH004904].

[13] R. Deng, Y. He, Y. Qin, Q. Chen, L. Chen, J. Remote Sens., 16 (1), 192 (2012).

[14] V.I. Yusupov, V.M. Chudnovskii, V.N. Bagratashvili, in Hydrodynamics - advanced topics, ed by H. Schulz (InTech, Rijeka, 2011), p. 95-118. DOI: 10.5772/28517 